\title{
Augmented reality of traditional food for nutrition education
}

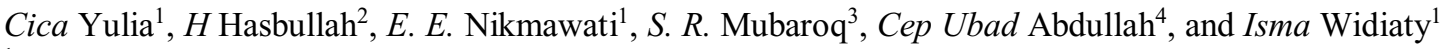 \\ ${ }^{1}$ Universitas Pendidikan Indonesia, Department of Home Economics, Bandung, Jawa Barat, Indonesia \\ ${ }^{2}$ Universitas Pendidikan Indonesia, Department of Electrical Engineering Education, Bandung, Jawa Barat, Indonesia \\ ${ }^{3}$ Universitas Pendidikan Indonesia, Department of Mechanical Engineering Education, Bandung, Jawa Barat, Indonesia \\ ${ }^{4}$ Universitas Pendidikan Indonesia, Department of Physical Education, Bandung, Jawa Barat, Indonesia
}

\begin{abstract}
This study aims to develop an augmented reality medium of traditional Sundanese food for nutrition education for teenagers. The media designed also consists of values of local wisdom education. The application is named AR Ma'Ugiz. The making of the application starts with story board design, 3D objects of traditional Sundanese food design using blender software and making videos about the making of the food. To make the videos, this paper uses Wondershare Filmora software. In an attempt of making AR Ma'Ugiz compatible to many platform, a Unity 3D is employed. The results of the research show that Augmented Reality designed to introduce traditional Sundanese food to teenagers is interesting and fun for them. In addition, the teenager students have more opportunities to explore the food in terms of the making procedure and nutrition information. Thus, the media used in nutrition education appear to have strengths in introducing values of local wisdom. In the meantime, local wisdom plays an important role in character education which, in this context, enables students to love their culture, including their traditional food.
\end{abstract}

\section{Introduction}

Traditional food represents a taste of pleasure, culture, belief, and identity of a certain area. Besides, it is also a symbol of heritage, trademark, and culture [1]. In this era, traditional food gives food quality and variation which becomes an alternative food choice. Studies show that traditional food has positive contribution for health since in terms of composition it has various natural nutrition [2]. For teenagers who seem to be addicted to fast food, traditional food can be a healthier food alternative. Fast food, as proven by research results, has potentials to lead to obesity and malnutrition [3] [4].

In relation to that, nutrition education for teenagers is crucial, particularly for active and healthy lifestyle [5]. Adolescence is an important period for optimum health and development [6]. An intervention program through nutrition education for teenagers need to be integrated among family, school, and government [6]. However, an ideal nutrition education should employ media which consider gender, maternal education, and dietary education aspects which will be influential for nutrition education for teenagers [7]. In this globalization era, one of the best ways in nutrition education for teenagers is through digital education media [5][8][9].

Educative media for teachers should pay attention to such aspects as the users of the media [10], interesting and relevant terms for teenagers i.e. "food hero" [11], balanced needs of nutrition for teenagers [12], and appropriately interesting media for teenagers [7].

A variety of media can be a good tool to convey the messages of "wisdom", such as single media (pictures, texts), multimedia (a series of texts, pictures, animation), computer-based media, and media combining real world and virtual reality namely Augmented Reality (AR). Augmented Reality (AR) can also be used in culture preservation [13] [14], vocational education [15], early childhood education [16], in laboratories [17], and in contents (knowledge) of education [18]. Thus, AR is considered effective and appropriate to be promoted in nutrition education for teenagers considering their characteristics.

This study aims to develop educative media of nutrition education for teenagers based on local wisdom of traditional Sundanese food utilizing a technology namely Augmented Reality (AR). In this study, the contents of educative media for nutrition education especially in making Sundanese food as an alternative for fast food. The media also contain information on the nutrition of several types of traditional Sundanese food so that teenagers can have adequate understanding and proper knowledge about healthy food they need to consume.

\section{Material and method}

The educative media utilizing AR to promote local wisdom for teenagers in this study is name "AR Mau'giz Application". The development of the application consists of several steps including making 3D objects using blender software and making videos through storyboard. Types of food explained in this application are "Burayot" (a Sundanese traditional pancake), "Bandrek" (a Sundanese traditional beverage with

\footnotetext{
* Corresponding author: cicayulia@upi.edu
} 
ginger), and "Lotek" (a Sundanese vegetable salad with peanut sauce), etc.

Videos are made and rendered using Wondershare Filmora software. The videos are about ingredients and processes of making Lotek, Burayot, and Bandrek. The next step is making AR Ma'Ugiz using Unity3D software. This software is selected due to its compatibility and accessibility of many platforms [19]. Prior to the use of Unity3D, SDK extension for Vuforia should have been installed to be able to use Augmented Reality features. SDK Extension itself can be downloaded through Vuforia website (https://developer.vuforia.com/resources/sdk/unity).

Figure 1 shows the flowchart of AR Ma'Ugiz. Users of the application will be asked to fill in usernames and passwords on the LOGIN form (see Figure 22). If the usernames or passwords are incorrect (not in the database), there will be an alert that brings the users back to the LOGIN form. When the login is successful, the camera will be active and able to detect markers in the AR Ma'Ugz books. The camera will always be active until it detects the markers. After the markers are detected, the application will determine whether they are 3D or videos. The 3D markers will detect and display 3D objects. Meanwhile, when the markers are videos, there will be a video player equipped with play, pause, stop, and exit buttons. The camera will be automatically inactive when the video players is running.

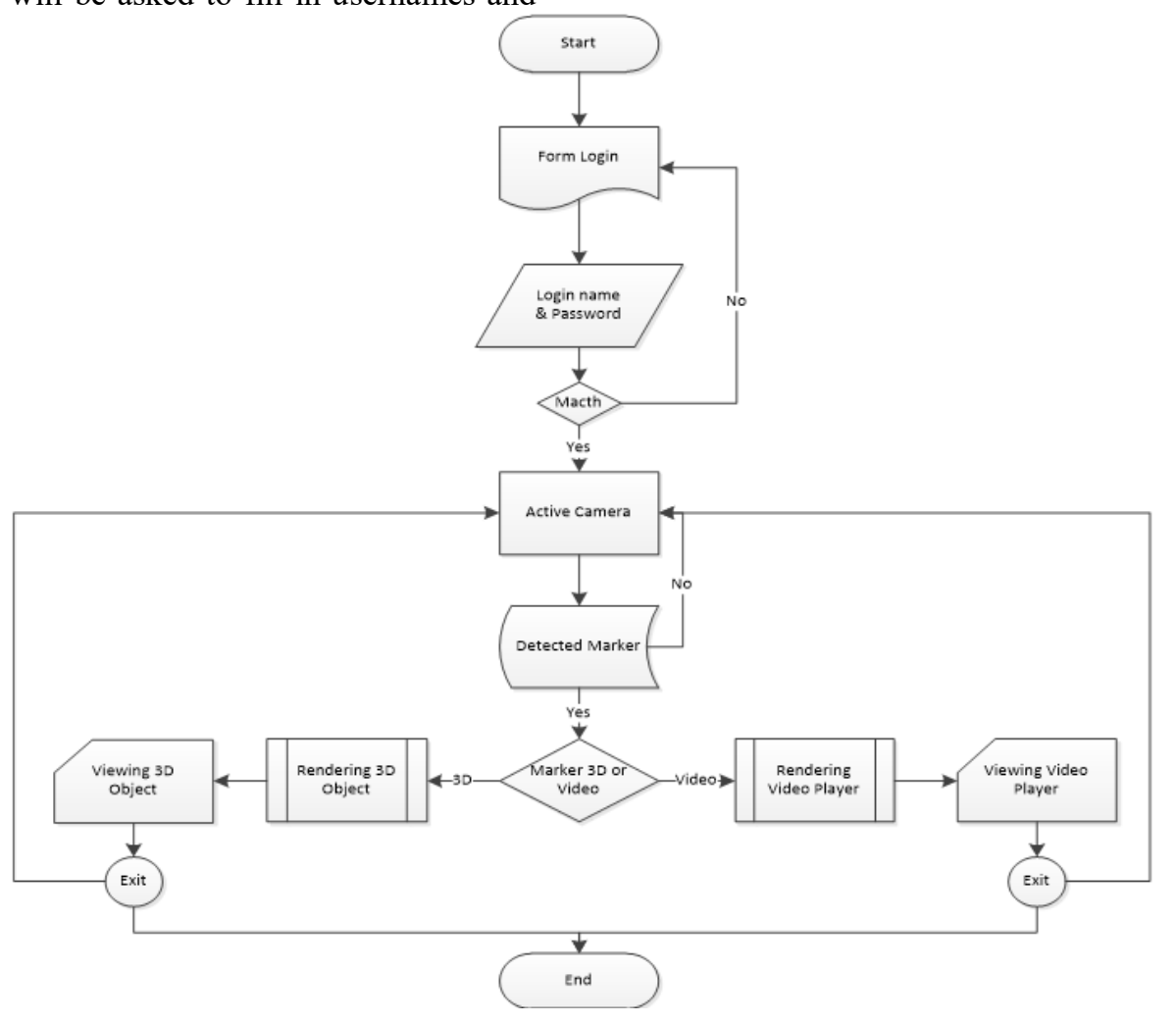

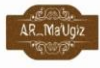

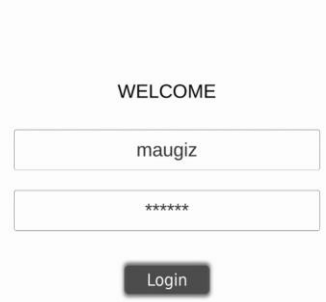

Fig. 2. Login form of AR Ma'Ugiz.

\section{Results and discussion}

The development of educative media of nutrition education for teenagers is designed in a form of a book. The book, namely AR Ma'ugiz, helps its users to learn about traditional Sundanese food along with the AR Ma’Ugiz application. This marker helps users to learn

18

Fig. 1. Flowchart of AR Ma'Ugiz.

Sundanese traditional food by scanning the food through AR Ma'Ugiz. The book of AR Ma'Ugiz itself using Adobe Illustrator application.

The book consists of cover and such topics as traditional Sundanese food, snacks, measured food, Sundanese traditional drink, Lotek, Burayot, and Bandrek. In the page(s) of measured food, there are several pictures of traditional Sundanese food functioning as markers for the application. Those markers are pictures made by Vuforia SKD application so that they can be detected by AR Ma'Ugiz. One of the strengths of markers made by Vuforia SKD is that they are not monochrome so that AR Ma'Ugiz can easily recognize them. For the images to be able to be used as markers, those images should be uploaded as target managers to database provided by Vuforia. The target manager can be accessed at https://developer.vuforia.com/target-manager and downloaded using “*.unitypackage” format. 
AR Ma'Ugiz application and book have been designed. Figure 3 shows the results of the trial of the application on the measured food page (Figure 3a). Meanwhile, names of the traditional Sundanese food will be shown on the application (Figure 3b).

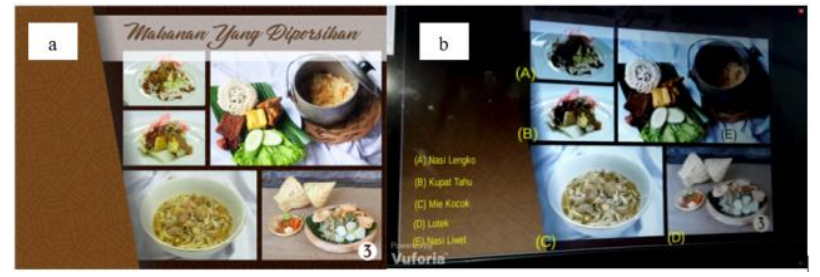

Fig. 3. The use of AR Ma'Ugiz on the measure food page on the book.

Figure 4 depicts the example of markers scanning results for videos. The markers on the book (Figure 4a) are identified by the application as markers to reveal a video player showing the procedure of making Lotek and nutrition information of it (Figure 4b).
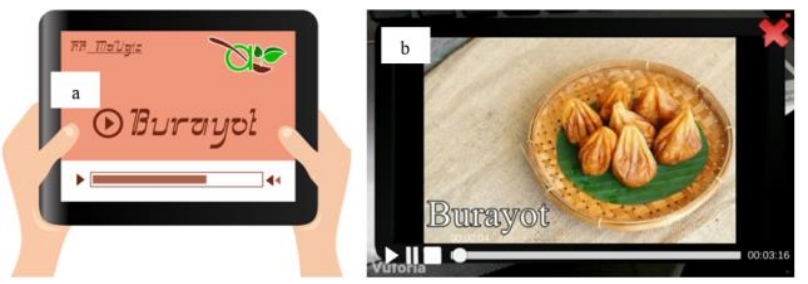

Fig. 4. Scanning results by AR Ma'Ugiz application for video markers.

Figure 5 shows scanning results of markers for 3D objects. The makers on the book (Figure 5a) are recognized by the application as markers that show a video player running the making of lotek and explaining nutrition information of it (Figure 4b).
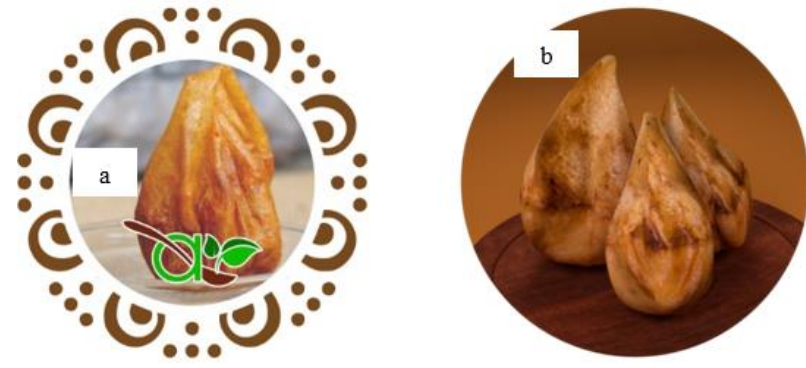

Fig. 5. Scanning Results by AR Ma'Ugiz application for 3D objects markers.

The function of AR Ma'Ugiz application using black box technique is to test the functions of features on the application. The test is done through five steps/ aspects. Based on the results of the test, it can be concluded that every feature on the application runs well.

The first aspect is related to the installation of APK files in a sense whether there is proper installation on Android-based smartphones. The second aspect of test is whether the application is opened well. The third aspect is related to the login form. To check whether it is running well or not, one of the ways is that unregistered accounts will be brought back to the login form when they try to login, while registered ones can directly access the camera to detect markers. The fourth aspect is related to marker detection; the results of the test show the $3 \mathrm{D}$ objects or a video player when it is installed properly. The last aspect is related to buttons on the video player (exit, play, pause, and stop). The good results of the test should perform each button as designed.

After the five aforementioned aspects of test, there needs to be a next test related to the time response when the application is run. This is necessary since the number of $3 \mathrm{D}$ objects to show is relatively high. The test is done to find out the specification of minimum devices able to run AR Ma'Ugiz. Thus, the test is done on three devices with different specification. Those three devices use at least Android v4.2, since AR Ma'Ugiz uses minimum API level of Android 4.2. (Jelly Bean). The results show that a device should have at least RAM 2GB and Quadcore $1.2 \mathrm{GHz}$ processor to be able to run the application. In other words, devices with that specification or above are able to run it well.

\section{Conclusions}

It has been proven that AR Ma'Ugiz is interesting as well as fun for teenagers in promoting nutrition education and local wisdom education. The application is also user-friendly since Android smartphones, the device in which the application is run, are owned by most of teenagers in Indonesia. It has also been shown that presenting videos of the procedure making and nutrition information of a certain type of food is the most favorite feature of the application. This fact is in line with a number of students which agree that in this era, the use of media should follow the students' needs and interests at the same time.

It is expected that Augmented Reality - Based Media be used in other topics and other subjects since it is easily designed and easily used. It is also expected that AR be used in other levels of schooling so that students in every grade learn things in a fun way.

\section{References}

1. M. S. M. Sharif, M. S. M. Zahari, N. M. Nor, and R. Muhammad, The Importance of Knowledge Transmission and its Relation towards the Malay Traditional Food Practice Continuity, Procedia Soc. Behav. Sci., 222, 567-577 (2016)

2. Z. Du Plooy, H. C. Schönfeldt, N. Hall, The role of traditional foods in food-based dietary guidelines A South African case study on maas (cultured milk), Food Chem., 238, 22-28 (2018)

3. D. McPhail, G. E. Chapman, B. L. Beagan, Too much of that stuff can't be good': Canadian teens, morality, and fast food consumption, Soc. Sci. Med., 73, 2, 301-307 (2011)

4. W. N. Ajie, K. M. Chapman-Novakofski, Impact of computer-mediated, obesity-related nutrition 
education interventions for adolescents: A systematic review, J. Adolesc. Heal., 54, 6, 631645 (2014)

5. M. Nour, S. H. Yeung, S. Partridge, M. AllmanFarinelli, A Narrative Review of Social Media and Game-Based Nutrition Interventions Targeted at Young Adults, J. Acad. Nutr. Diet., 117, 5, 735752 (2017)

6. S. Meiklejohn, L. Ryan, C. Palermo, A Systematic Review of the Impact of Multi-Strategy Nutrition Education Programs on Health and Nutrition of Adolescents, J. Nutr. Educ. Behav., 48, 9, 631-646 (2016)

7. D. Tamiru, A. Argaw, M. Gerbaba, A. Nigussie, G. Ayana, T. Belachew, Improving dietary diversity of school adolescents through school-based nutrition education and home gardening in Jimma Zone: Quasi-experimental design, Eat. Behav., 23, 180186 (2016)

8. A. Dunne, J. McIntosh, D. Mallory, Adolescents, Sexually Transmitted Infections, and Education Using Social Media: A Review of the Literature, J. Nurse Pract., 10, 6, 401-408 (2014)

9. T. M. Leak, L. Benavente, L. S. Goodell, A. Lassiter, L. Jones, S. Bowen, EFNEP Graduates' Perspectives on Social Media to Supplement Nutrition Education: Focus Group Findings from Active Users, J. Nutr. Educ. Behav., 46, 3, 203-208 (2014)

10. E. K. Murray, G. Auld, R. Inglis-Widrick, S. Baker, Nutrition Content in a National Nutrition Education Program for Low-Income Adults: Content Analysis and Comparison With the 2010 Dietary Guidelines for Americans, J. Nutr. Educ. Behav., 47, 6, 566573 (2015)

11. L. N. Tobey, M. M. Manore, Social media and nutrition education: The food hero experience, J. Nutr. Educ. Behav., 46, 2, 128-133 (2014)

12. J. Lee, S. Jeong, G. Ko, H. Park, Y. Ko, Development of a Food Safety and Nutrition Education Program for Adolescents by Applying Social Cognitive Theory, Osong Public Heal. Res. Perspect., 7, 4, 248-260 (2016)

13. D. Cianciarulo, From local traditions to 'Augmented Reality'. The MUVIG Museum of Viggiano (Italy), Procedia-Social Behav. Sci., 188, 138-143 (2015)

14. M. Puyuelo, J. L. Higón, L. Merino, M. Contero, Experiencing Augmented Reality as an Accessibility Resource in the UNESCO Heritage Site Called 'La Lonja', Valencia, Procedia Comput. Sci., 25, 171-178 (2013)

15. J. Bacca, S. Baldiris, R. Fabregat, Kinshuk, S. Graf, Mobile Augmented Reality in Vocational Education and Training, Procedia Comput. Sci., 75, 49-58 (2015)

16. R. M. Yilmaz, Educational magic toys developed with augmented reality technology for early childhood education, Comput. Human Behav., 54, 240-248 (2016)

17. M. Akçayır, G. Akçayır, H. M. Pektaş, M. A. Ocak, Augmented reality in science laboratories: The effects of augmented reality on university students' laboratory skills and attitudes toward science laboratories, Comput. Human Behav., 57, 334-342 (2016)

18. C. Diaz, M. Hincapié, G. Moreno, How the type of content in educative augmented reality application affects the learning experience, Procedia Comput. Sci., 75, 205-212 (2015)

19. J. W. Oak, J. H. Bae, Development of smart multiplatform game app using Unity $3 D$ engine for CPR education (2014) 